\title{
Design of Class Components for Laparoscopy Surgery Simulation with Haptic Elements: A Case Study of SPLasH
}

\author{
Norkhairani Abdul Rawi, Halimah Badioze Zaman, and Azlina Ahmad
}

\begin{abstract}
Minimal invasive surgery or laparoscopy has taken part especially for pediatrics. Traditionally, medical students learn surgical skills through the mentorship model during their residency training. As technology evolves, more and more applications, simulations and system are built as aids to medical students in acquiring surgical skills. This research is conducted to identify how haptics technology can play part in shaping student skills in Surgery Department of HUKM. This paper will discuss the second phase of the research: Design and Development that focus on simulation class structure based on preliminary analysis. Results show that current training approaches have some weaknesses that can be replaced by applying simulations with haptics devices. Proposed structure will be tested in development stage. It is a hope that this research will enrich the literature review for visual informatics area.
\end{abstract}

Index Terms-Haptic, laparoscopy, simulation, surgery.

\section{INTRODUCTION}

Skill is used as measurement in determining individual competency. Skill can be divided into soft skill and physical skill. Soft skill is more towards how people deal with other people, which focused on communication, presentation and etc [1]. Physical skill or called technical skill focused on how people carried out task that need specific steps or procedure, and normally deal with equipment or devices.

Skill normally acquired through the teaching by the expert together with consistent practices [2], [3]. More time spent between experts and trainee will increase the skill acquisition. In medical field, especially in surgery, researches is carried out to reduce the incision in surgery that lead to the implementation of MAS (minimal access surgery) or known as laparoscopy. This procedure needs high skilled surgeons to operates, and the skill is quite difficult for the surgical trainee to master it [2], [3]. The most difficult part is on the pressure and grasp that should be given towards the muscle. Therefore, there is a need for surgical trainee to spend more time with the experts to acquire the skill under experts' supervision.

Manuscript received January 9, 2013; revised May 2, 2013.This research has been funded the Government of Malaysia by a grant under Projek Arus Perdana (UKM-AP-ICT-16-2009) entitled 'Multi-Display Interactive Visualization Environment on Haptic Horizontal Surface (Mi VH Tabletop)'

F. Norkhairani is with the Faculty of Informatics, Sultan Zainal Abidin University, Gong Badak Campus, 21300 Terengganu, Malaysia (e-mail: khairani@unisza.edu.my).

S. Halimah and T. Azlina are with Institute of Visusal Informatics, National University of Malaysia, 43600 Selangor, Malaysia (e-mail: hbz@ivi.ukm.my, aa@ivi.ukm.my).
Anyway, there are some issues arise such as limitation of time, social and financial that restricted the experts to spend more time in training the trainee [3].

This issues has then lead to the uses of technology as an effort to help the trainee doing frequent and consistent training. Robotics, simulation and virtual training system are technology that available to fulfil this gap [4]. Besides that, the usage of dummy also helps in the acquisition of surgery skill [4]. Simulation is one approach that seems accepted as tool for skill training with the integration with haptic devices that provide force feedback and tactile to increase realism [5].

In Visual Informatics areas, this kind of integration which interdisciplinary has attracted a great attention from researchers in recent years [6]. Many of research carried out in visual informatics system eventhough in the mass market, this systems is not prominent [6].

In our country, the usage of haptics device can be considered as new but the research in this area is growing. This research is conducted to discover how simulation for laparoscopic surgery training with haptics elements or SPLasH (Simulasi Pembedahan Laparoskopi dengan Elemen Haptik) that integrate visual informatics component, can be implemented at surgery department for medical student training at HUKM (Hospital Universiti Kebangsaan Malaysia). The main focus of this research to provide a simulation that can represent almost accurate pressure and grasp level. The procedure of hernia repair has been chosen as subject to be simulated. The research is divided into three main phase:

1) The Preliminary Analysis of SPLasH requirement

2) The Design and Development of SPLasH simulation

3) User acceptance test towards SPLasH as tool aid for laparoscopy surgery training at HUKM

The preliminary analysis has been carried out and identified few major issues need to be catered. One of the most important findings is current training method didn't provide an appropriate pressure and grasp experience to the trainee where this elements is a vital part of the procedure [1].

This paper will discuss findings of the preliminary analysis of this research on pressure and grasp elements and how haptics device can be implemented to represent the elements. Major component of proposed simulation also will be explained briefly.

\section{LITERATURE REVIEW}

Laparoscopy is a minimally invasive procedure that is used either to diagnose diseases or as method of surgery [7]-[9]. It normally applies to those procedures that cannot be detected 
through diagnostic imaging such as pelvic pain by gynaecologist, and also used in normal procedure to examine abdominal organs. Laparoscopy started with a small incision to accommodate the insertion of laparoscope instruments through cannula or trocar and normally under the navel. Other incisions also made to allow other insertion of laparoscopy additional instruments and normally both in left and right abdomen. Once the procedure completed, the instruments will be removed and the incision will be sutured and bandaged. This incision will take shorter time to recover and patients don't need a long stay at the hospital. Sometimes they treated as daily patients instead of in home patients [7]-[9]. The use of instruments is fully handled with certain pressure and grasps level to achieve the completion of procedure. These procedures need proper training [10] to be mastered. Due to that requirement, models have been developed to fulfill this need [11].

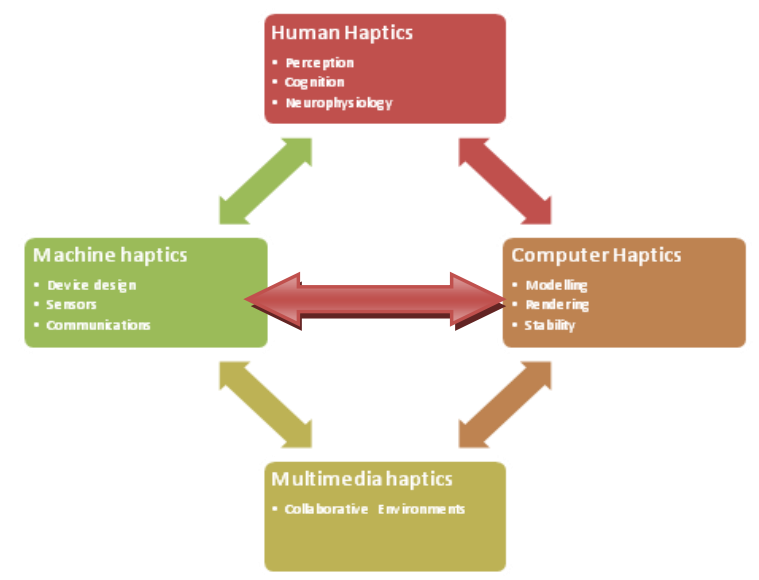

Fig. 1. Multidisciplinary research in haptics [22].

Currently, there are many application has been developed to be used as training aid for minimal invasive surgery (MIS) or laparoscopy [12]-[14]. SINERGIA laparoscopic virtual reality simulator is an application that provide exercises for specific skill acquisition - coordination, speedy coordination, navigation, navigation and touch, accurate grasping, grasp and transfer, coordinate pulling, force sensitivity and accurate cutting [12]. The MISTELS system (McGill Inanimate System for Training and Evaluation of Laparoscopic Skills) has been designed to provide a series of tasks that performed under video guidance in a box using standard laparoscopic instruments to objectively assess basic laparoscopic skills [14].Another virtual reality simulator that is computer based developed is MIST-VR (Mentice AB, Gothenburg, Sweden) that includes interfaces with two laparoscopic instruments passed through a frame containing a tracking device [13]. MIST-VR provides basic skills training (core skills 1 and 2) under module 1 and module 2 for intracorporal suture training.

The benefits of using haptics devices in surgical simulation have been realized by many parties' inclusive researchers and companies. Few companies that really put an effort in this particular area, for example are Imersion Medical, Mentice, Surgical Science and Reachin [15]-[17]. This has led to the growth of research in haptics and simulations.

Haptics according to Fisher et al is to be touched, as visual to be seen and as auditory to be heard while Oakley et al defines haptics as something that related to the sense of touch
[18]-[20]. Haptics is possible to be implemented in four areas which is human haptics, computer haptics, multimedia haptics and machine haptics [21]-[23]. Research related to haptics has moved to multidisciplinary that involved the four main areas as shown in Fig. 1 [22], [23].

Each of the area focused in different aspects of haptics technology but interrelated to each other. Human haptics is an area that focused on human sensory motor loop and all related aspects with human perception towards sense of touch. Machine haptic focused on mechanical devices that replace or augment the human touch. Human haptics involve with design and development of mechanical devices. The mechanical devices needs a life to be felt by the user where this is the part played by the computer haptics. It focused on algorithm development and software to produce sense of touch to the virtual object through haptic visual and rendering. While multimedia haptic is referred as the integration and synchronisation haptic interfaces data presentation, with other media, in multimedia application that utilized gesture recognition, tactile sense and force feedback [21], [22]. The integration of this four areas enables the visualizalition of information that enhance features in visual informatics area.

Haptic development in medical has an abundant source. Many surgical procedures has revolutionised it's media training through the exploration of haptic technologies over the last few decades [22]. Research in surgical simulators potentially addresses many of the issues in surgical training such as [22];

1) It can generate scenarios of graduated complexity

2) New and complex procedures can be practiced on simulator before move to the human or animal

3) Students can practice on their own schedule and repeat the sessions as many times as they want without depending on experts to guide them

Simulation for laparoscopy surgery requires a specially design instruments and environment [15], [22] and few challenges raised in developing a training set. Haptic interface hardware design, tissue and organ development model, interactions between tools and tissues, real-time rendering of graphic and haptic and not to forget recording and playback has been surrounded the researcher in this area [22] and become a motivation to encourage more and more research carried out to improve the simulation or training aid to assist surgeons especially for two main elements in laparoscopy which are controlling grasp and pressure.

Teaching surgical skills has been debated for a long time [2]-[4], [9], [10], [24] and identify few issues need to be catered in developing training aid for the medical students or novice surgeons which has then led to the increase of study in skill training and development of learning aid. Even though many research has been carried out recently on laparoscopy surgery skill training [4], [5],[8], technologies and modeling of tissues [25]-[27] and also development made for laparoscopy skill training [12], [14]-[16], [18], [21], [24], [28]-[30] but most of the application developed or experiment carried out focuses on task but none of it provide for a single and complete surgery procedure such as hernia repair, cyst remove and etc. Research in grasp control shown that surgeons perform better if suitable application that provide force feedback thus help them in improve their skill ability [28]-[30]. This is the main reason why this research focuses on this vital skill. 


\section{THE GRASP}

It is define as the combination of pinch and pull force. The level of grasp towards the body tissue must be within the safe area as shown in Figure 1. The boundaries of the safe area are formed by the damage line and the slip line [28]. The damage line is the boundary above where the tissue can be damaged due to certain combination of pinches or pulls force. While the slip line is the boundary below where the tissue can be damaged due to certain combination of pinch or pull force. Few factors influence how safe is the grasp such as:

1) The details of the jaws

2) The details of mechanicals of tissue

3) Pressure that givens towards the tissue during grasp

It is important to give the correct grasp level to avoid tissue damages or slippage. Tissue damage is a result of excessive force during grasp while tissue slippage occurred when insufficient control of pinch given to the tissue. Both of these situations can lead to tissue trauma. Frequent study towards this matter has been carried out and reported [27]-[30]. Device development to represent grasp virtually [31] also rising up. Few research also done on effective grasp control The average of grasp level that should be given is $8.5 \mathrm{~N}^{ \pm} 2.8 \mathrm{~N}$ while the maximum level is $24.9 \mathrm{~N} \pm 8.1 \mathrm{~N}$ [32]. Fig. 2 illustrated below shown the safe area zone which is bounded by slip and damage forces. The more pull force and the pinch force will contribute to damage line and slip line.

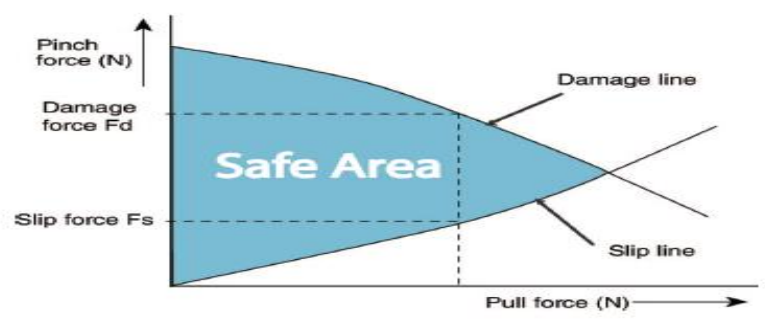

Fig. 2. Safe area bounded by slip and damage forces. adapted from de visser (2002) [28].

\section{The Pressure}

The best pressure level for intra-abdominal is between 10 to $15 \mathrm{mmHg}$. The higher pressure which is within 15 to 20 $\mathrm{mmHg}$ is suboptimal. This is due to the correlation between discomfort and patients recovery after procedure. The pressure above $20 \mathrm{mmHg}$ is classified as dangerous because it has a potential of hemodynamic and pulmonary compromise also there is long term effects towards internal wall tissue of abdomen [33].

\section{DISCUSSION}

Preliminary analysis study has been carried out to identify how current methods in laparoscopy surgery training are carried out at surgery department of HUKM and weaknesses will be replaced with haptics devices where appropriate [1]. Two major issues has been identified during the study as discussed below.

\section{A. Current training method}

Currently the students at surgery department of HUKM are using dummy box set (Fig. 3) that comprises of two part, upper and lower. The upper part (Fig. 4) contains a surface abdomen like that make from foam. The lower part is an empty box (Fig. 5) that acts as internal part of the abdomen. Through an observation and interview, it clearly can be seen that the dummy only can provide the constraints like abdominal wall on the first time of insertion that may lead to accurate force given to the abdominal wall [1]. The hole will stay there when the next student is trying to do insertion. The constraints is much lesser compared to the first time. Furthermore there is no method or device is used to measure the pressure given by the students onto the abdominal wall.



Fig. 3. The complete dummy box set.

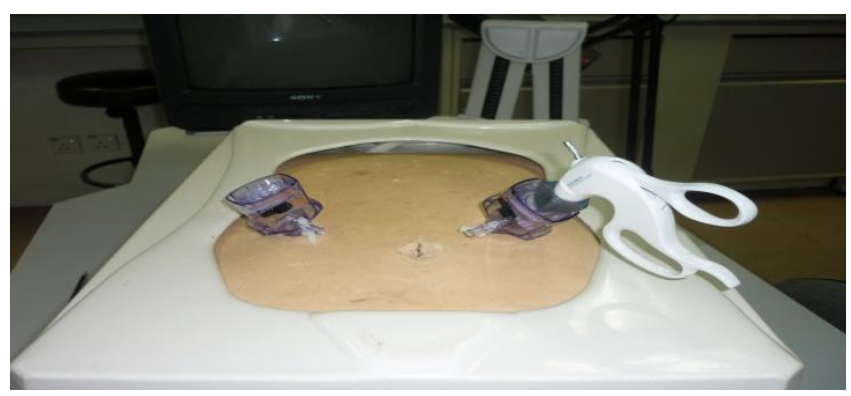

Fig. 4. Upper part.

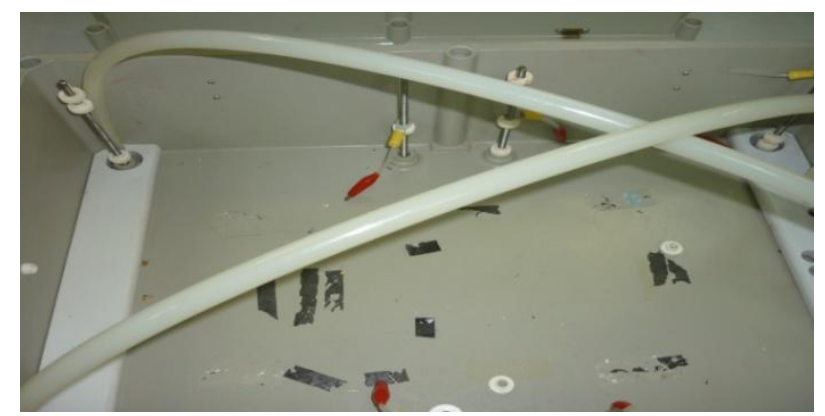

Fig. 5. Lower part

To overcome this issue, a simulation has been designed to replace the dummy box. The application will be developed in few phases:

1) Prepare the $3 \mathrm{D}$ model (abdomen and instruments)

2) Design the algorithm to control the haptics devices (PhantomOmni has been chosen as the device)

3) Integrate model and haptics device

4) Measure the force setting

The force can be computed in three common ways which known as motion dependant or time dependant or both ways. In this case study, the force control under motion dependant type spring which is more versatile and simple to use [31]. A spring force is computed using Hooke's Law ( $F=k x$, where $k$ is a stiffness constant and $\mathrm{x}$ is a displacement vector) [31].

\section{B. Realism Lost}

Since the upper part only provides constraint on the first time usage only, the realism of human anatomy won't be felt 
on the second time and so on. The lower part of dummy is place to put an organ for the trainer to manipulate (grasp and do suturing). This organ is not well connected to the wall, as what we have in human abdominal wall. Again, lost of realism occurred. By applying 3D modeling and usage of haptics device to represent the instruments of laparoscopy procedure, the student will feel the immersiveness and yet help them acquire the intended skill.

\section{PRoposed Class Components}

After an extensive review towards the ability of OpenHaptics Toolkit (since we are going to use Phantom Omni), four main class has been identified need to be catered in SPLasH.

\section{A. Device Space Class}

Conceptually the device space class defines the force properties and user interaction through haptic workspace for Phantom Omni. It manages force effects and user call backs. Force effects can be divided into friction, damping - degree of difficulty when moving through the space (in this case when user insert the verees needle to initiate an incision) and also constant force. User callbacks are a function calls that occur as a result of an event such as motion, haptic touch or button press. For this study, device space will define the environment for surgical simulation. It has been summarised as listed in Table I. It is a visualization of abdomen of pediatric in three phases:

TABLE I: Phase of DeVice Space Class

\begin{tabular}{|l|l|l|}
\hline Phase & Visual & Purpose \\
\hline First & External part & $\begin{array}{l}\text { For pre procedure such as insertion of } \\
\text { laparoscopy and the incision position of } \\
\text { equipments. During the incision making } \\
\text { process the 2 pop techniques in making } \\
\text { incision will be implemented (2 pop is a } \\
\text { process where the layers of abdomen wall } \\
\text { giving constraints while making incision) }\end{array}$ \\
\hline Second & Internal part & $\begin{array}{l}\text { The main process taking where the insertion } \\
\text { of jaws can be seen, also the area that needs } \\
\text { to be "corrected" (for this study is hernia } \\
\text { repair). The view how needle and jaws is } \\
\text { cooperating correcting the hole and suturing } \\
\text { process. }\end{array}$ \\
\hline Third & External part & $\begin{array}{l}\text { When the equipment has been pulled out, } \\
\text { only small incision left and no need for } \\
\text { bandages and etc. Only navel need to be } \\
\text { stitch back and the procedure ends. }\end{array}$ \\
\hline
\end{tabular}

\section{B. QHWin32/QHGLUT Class}

This class act as windowing classes that inherits from the QHRenderer class that defines the following:

- Simple display list for haptics and graphics (in this study the Phantom Omni, the abdomen model and the instruments)

- OpenGL world space to PHANTOM device space transformation

- Simple camera and lighting model

World space is developed using OpenGL (Open Graphics Library) standard that project three-dimensional frustrum and known as 3-D space. It can be describe and addressed by coordinate system. Mapping between the device space and the world space is applied using scaling factor. This may result a small movement of the haptic device may scale up to much larger movement in the world space. This is very important if we have limited space of display on the screen. For this study it needs to be careful organised since the world space is combine with other portion of screen elements.

The camera establishes the viewpoint into the world space. Rather than forcing shapes to fit within the confines of a world space dictated by the camera, the default camera accommodates itself to the scene, to the shape created within the scene.

\section{Shape Class}

This class defines the base class for all the geometry primitives that can be included in the world space such as line, cone, sphere, box etc. One of the classes defined is TriMesh class that represents a 3-D model produced by industry standard modeling programs such as SolidWorks, 3DsMax, Lightwave as long as the object in STL, OBJ, 3DS and PLY formats. The deformation of shape when touched by the haptic cursor is handled by a property. For this study, the abdomen model and the instruments is created using 3Ds Max and OpenGL. Euler integration is performed with a frame to a frame timestep. This is suitable to simulate elastic objects which only with TriMesh shapes [31].

\section{Cursor Class}

This class defines the haptic interface point. It pulls together information from all of the other classes mentioned above. Device space class provide information for the location of the haptic interface point because there can be more than one haptic device, there can be more than one cursor. For example for this study there will be two haptic devices, and two cursors that represent the device (grasper and needle).

World Space class provides information about the transformation that allows the device space cursor position to be drawn on the scene. For this study, this reflects to the space of internal abdominal wall where the procedure is taking place.

Shape class provides information about the objects with which the cursor will interact and how the cursor should be represented. For this study, the shape will be the abdomen (external and internal).

The cursor class default is a "blue cone". For this study, a TriMesh model will be loaded as the cursor will be represented by the instruments that used in the procedure (verees needle, jaws/grasper, laparoscope and needle with thread). Basically, the whole components are going to be define as shown in Fig. 6.



All the class mentioned above will be design and tested to fulfill the need of accurate grasp and pressure for laparoscopy surgery and for this case is specifically for hernia repair procedure. Experienced surgeons will be involved in setting 
right level of pressure and grasp before usability testing carried out by medical students. It is a hope that this simulation will assist medical students acquire skills needed for laparoscopy surgery since currently there is no computer assisted tool provided for training in this skill area at HUKM.

\section{CONCLUSION}

Study towards providing a good simulation and training tool to assist surgeons training has taken great attention from researcher. These has been done to overcome tissue trauma that caused by excessive grasp forces [28], [29]. This study is carried out to provide a learning aid that not focuses on series of tasks but a complete procedure that involve basic skill in laparoscopy surgery. The design of the simulation need to be carefully design in order to improve current training method and to present realism to the trainee in order to ensure the acquire the right skill. The class proposed in this paper will be developed in $\mathrm{C}++$ and Opengl.

\section{ACKNOWLEDGMENT}

The author like to thank the Visual Informatics (VI) group of Institute of Visual Informatics, UKM and especially to Prof. Dato' Dr. Halimah Badioze Zaman and Associate Prof. Dr. Azlina Ahmad for supervising this research. Author also would like to thank Dr. Dayang Anita Abdul Aziz (HUKM) for technical advices on laparoscopy procedure and Dr. Azlan from CORE Experts Systems for technical advices and guides on simulation development.

\section{REFERENCES}

[1] A. R. Norkhairani, B. Z. Halimah, and A. Azlina, "Development of Simulasi Pembedahan Laparoskopi dengan Elemen Haptik (SPLasH) For Medical Students in HUKM: A Preliminary Analysis," presentd at Second International Visual Informatics Conference, LNCS, Kuala Lumpur: Springer, pp. 125-138, 2011.

[2] J. A. Wong and E. D. Matsumoto, "Primer: cognitive motor learning for teaching surgical skill-how are surgical skills taught and assessed?" Nature Clinical Practice Urology, vol. 5, no. 1, pp. 47-54, 2008.

[3] J. M. Hamdorf and J. C. Hall, "Acquiring surgical skills," British Journal of Surgery, vol. 87, no. 1, pp. 28-37, 2000.

[4] A. Najmaldin, "Skills training in pediatric minimal access surgery," Journal of pediatric surgery, vol. 42, no. 2, pp. 284-289, 2007.

[5] L. Panait et al., "The role of haptic feedback in laparoscopic simulation training," Journal of Surgical Research, vol. 156, no. 2, pp. 312-316, 2009.

[6] B. Z. Halimah et al., "Visual Informatics: Bridging Research and Practice," presented at First International Visual Informatics Conference, LNCS, Kuala Lumpur: Springer, pp. 5-6, 2009.

[7] J. Sándor et al., "Minimally invasive surgical technologies: Challenges in education and training," Asian Journal of Endoscopic Surgery, vol. 3, no. 3, pp. 101-108, 2010.

[8] R. S. Chamberlain and S. V. Sakpal, "A comprehensive review of single-incision laparoscopic surgery (SILS) and natural orifice transluminal endoscopic surgery (NOTES) techniques for cholecystectomy," Journal of Gastrointestinal Surgery, vol. 13, no. 9, pp. 1733-1740, 2009.

[9] N. M. A. Bax, "Ten years of maturation of endoscopic surgery in children. Is the wine good?" Journal of pediatric surgery, vol. 39, no. 2 , pp. 146-151, 2004.

[10] M. Laguna et al., "Training in Laparoscopy," Laparoscopic Urologic Surgery in Malignancies, pp. 253-269, 2005.

[11] J. Rosen et al., "Markov modeling of minimally invasive surgery based on tool/tissue interaction and force/torque signatures for evaluating surgical skills," IEEE transactions on Biomedical Engineering, vol. 48, no. 5, pp. 579-591, 2001.

[12] P. Lamata et al., "SINERGIA laparoscopic virtual reality simulator: Didactic design and technical development," Computer methods and programs in biomedicine, vol. 85, no. 3, pp. 273-283, 2007.
[13] A. J. Debes et al., "A tale of two trainers: virtual reality versus a video trainer for acquisition of basic laparoscopic skills," The American journal of surgery, vol. 199, no. 6, pp. 840-845.

[14] A. Sansregret et al., "Choosing the right physical laparoscopic simulator? comparison of LTS2000-ISM60 with MISTELS: validation, correlation, and user satisfaction," The American journal of surgery, vol. 197, no. 2, pp. 258-265, 2009.

[15] C. Basdogan et al., "Haptics in minimally invasive surgical simulation and training," Computer Graphics and Applications, IEEE, vol. 24, no. 2, pp. 56-64, 2004.

[16] C. Basdogan et al., "Virtual environments for medical training: Graphical and haptic simulation of laparoscopic common bile duct exploration," IEEE/ASME Transactions on Mechatronics, vol. 6, no. 3, pp. 269-285, 2001

[17] B. Dunkin et al., "Surgical simulation: a current review," Surgical endoscopy, vol. 21, no. 3, pp. 357-366, 2007.

[18] G. Niemeyer et al., "THUMP: an immersive haptic console for surgical simulation and training," Studies in health technology and informatics, pp. 272-274, 2004

[19] B. Fisher et al., "Seeing, hearing, and touching: putting it all together," ACM, 2004.

[20] I. Oakley et al., "Putting the feel in 'look and feel'," ACM, 2000.

[21] M. Eid et al., "HAMLAT: A HAML-based authoring tool for haptic application development," Haptics: Perception, Devices and Scenarios, pp. 857-866, 2008.

[22] M. Eid et al., "A guided tour in haptic audio visual environments and applications," International Journal of Advanced Media and Communication, vol. 1, no. 3, pp. 265-297, 2007.

[23] A. El Saddik, "The potential of haptics technologies," IEEE Instrumentation and Measurement Magazine, vol. 10, no. 1, pp. 10, 2007.

[24] P. Ström et al., "Early exposure to haptic feedback enhances performance in surgical simulator training: a prospective randomized crossover study in surgical residents," Surgical endoscopy, vol. 20, no. 9, pp. 1383-1388, 2006.

[25] R. Webster et al., "Elastically deformable 3D organs for haptic surgical simulation," Studies in health technology and informatics, pp. 570-572, 2002.

[26] S. Cotin et al., "A hybrid elastic model for real-time cutting, deformations, and force feedback for surgery training and simulation," The Visual Computer, vol. 16, no. 8, 2000.

[27] E. P. Westerbring-van der Putten et al., "Haptics in Minimally Invasive Surgery - a review," Minimally Invasive Therapy and Allied Technologies, vol. 17, no. 1, pp. 3-16, 2008.

[28] E. P. Westerbring-van der Putten et al., "Force Feedback requirements for efficient laparoscopic grasp control," Ergonomics, vol. 52, no. 9, pp. 1055-1066, 2009.

[29] E. P. Westerbring-van der Putten et al., "The Effect of Augmented Feedback on Grasp Force in Laparoscopic Grasp Control," IEEE Transactions on Haptics, vol. 3, no. 4, pp. 280-291, 2010.

[30] E. P. Westerbring-van der Putten et al., "The Opinion and Experience of Surgeons with Laparoscopic Bowel Grasper Haptics," Journal of Biomedical Science and Engineering, vol. 3, pp. 422-429, 2010.

[31] SensAble Technologies Inc. (2008). OpenHaptics ${ }^{\circledR}$ Toolkit Programmer's Guide. [Online]. Available: www.dsc.sensable.com.

[32] J. D. Brown et al., "Quantifying Surgeon Grasping mechanics in laparoscopy using the blue dragon system," Studies in Health Technology and Informatics, vol. 98, pp. 34-36, 2004.

[33] P. J. Quilici. (2003). Performing Safe Laparoscopy. Online Laparoscopic Technical Manual - Year 2003. [Online]. Available: www.laparoscopy.net

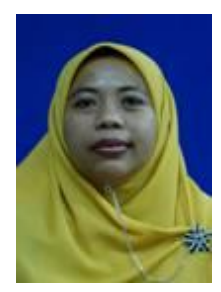

Norkhairani Abdul Rawi was born in Terengganu, Malaysia on 19th October 1975. She obtained Diploma in Information Technology from Sultan Zainal Abidin Religious College in 1996. After two years, in 1998 she graduated from National University of Malaysia (UKM) with a degree of Bachelor in Information Science and Technology. In 2004, completed the Master Degree in information science from National University of Malaysia. Currently is a $\mathrm{PhD}$ candidate in Visual Informatics group at National University of Malaysia since 2009.

She has been employed by Sultan Zainal Abidin Religious College as lecturer since 1998 under young lecturer scheme. She has been appointed as Head of Multimedia Programme for two years since 2003 to 2005. After the restructure of unit, she then appointed as Head of Multimedia Unit under Information Technology Center. In 2007, the college has been upgraded to University level and she has been appointed as lecturer at Faculty of Informatics, Sultan Zainal Abidin University. In 2009, she left the unit to 
pursue her study in PhD level at National University with the sponsorship by the government and the university. She has published a few papers in international and national conference to name some ISEL 2005, IETC 2004, IVIC 2011 and VIIS 2012.

Ms Norkhairani is a life time member of MITS (Malaysian Information Technology Society) since 2008.

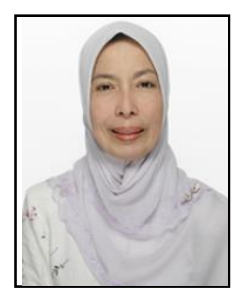

Halimah Badioze Zaman was born in Perak Malaysia on 30th September 1954. Professor Halimah Badioze Zaman obtained her first degree at London University in 1977. She then read for her Masters in Information Science at Loughborough University (United Kingdom) in 1980. In 1982 she obtained her $\mathrm{PhD}$ from the same University. Upon returning from her $\mathrm{PhD}$ in 1982, she joined the Faculty of Education, Universiti Kebangsaan Malaysia as one of its academic staff until September 1993. As she was one of the initiators of the Faculty of Information Science and Technology, UKM, she joined the new faculty on its inception on 1 October 1994. She became the first Head of Department of Information Science from 1 October 1994 till 30 September 2000. Prof Halimah is presently the Director of Institute of Visual Informatics, UKM. She is the lead researcher of four IRPA project which are Software Development to Motivate Literacy: A Multimedia Approach, Software Development in Mathematics for Smart Schools : A Multimedia in Education Approach, Development of an Intelligent Literacy System based on Learner profile and Learning Styles: a multimedia Approach; and Development of a Voice Recognition System for Learning Disabilities: A Multimedia Approach and co-researchers in 3 other IRPA and UKM research projects.

She has been consultant and Advisor to various organizations like, Ministry of Education, Ministry of Information, and MIMOS. She was also involved in various consultancy projects with private sectors. Has written various books and articles in journals and proceedings both at the National and International arenas mostly on IT/Multimedia in Education. Has also presented papers at numerous conferences both at the national and international levels in the said fields. Prof Halimah was one of the consultants to the Ministry of Education on the e-learning policy and ICT in Education policy for Malaysia.

Prof Halimah is presently President of the Malaysian Reading Association, Council Member of IDAC (International Development for Asia Committee) (USA), Council member of Literacy, Communications and IT, of the International Reading Association (IRA), USA, Committee member of the Malaysian Cognitive Science Association (COSMA), Member of IEEE, President and Member of Information Technology Society of Malaysia (MITS) and was a fellow researcher at London University and consultants to the Ministry of Education on the e-learning policy and ICT in Education policy for Malaysia. Last but not least, she is also a member of the National Information Technology Council (NITC) Working Group on E-Learning.

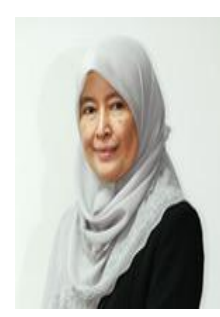

Azlina Ahmad was born in Negeri Sembilan, Malaysia on 1st July 1961. She obtained BS. and MS. from Indiana University. AP Dr Azlina then complete her PhD from Malaya University, Malaysia. Dr Azlina has been employed by National University of Malaysia as lecturer since 1985. Dr Azlina has been appointed as committee in various board during her services. Dr. Azlina is Secretary of International Visual Informatics Conference 2009 (IVIC'09) Faculty 2009, Assistant Secretary of International Symposium on Information Technology 2010 (ITSim'10) National 2009, Committee Member of Action Plan Group for Internationalisation of IPTA and IPTS Ministry of Higher Education. National 2008, Secretary of International Symposium on Information Technology 2008 (ITSim'08) National 2007, Committee Member of Teaching and Equipment Faculty Since 2007, Committee and Member of Examination Questions Faculty Since 2007, to name a few.

She also have numerous research projects such as Virtual Robotics Lab, Process Control using Interactive Simulation in a Virtual Factory, Holistic Virtual Reality Futures Lab based on Voice-Haptic-Intuitive and Interactive Visualisation Approach (Visi-Lab), Development of an Islamic Corporate and Retail Banking System (CORE): A Multi-tiered Architecture, Development of a Virtual Reality Visualisation Laboratory to Build Virtual Worlds for Learning, Development of an Advanced Multimedia in Special Education System for Learning Intervention, Cognition and Multimedia Instructional Design for Learning, Development of A Multimedia-based Cognitive Tool For Learning Fractions and Solving Word Problems Involving Fractions, Parallel Algorithm Implementation For The Solution of (RM550,000), Development of CAD System for Product Design and Spesifikasi Rekabentuk Fesyen dibantu Komputer. She also involved in few design and have few trademark. She has various publication internationally and nationally.

Dr Azlina has joined as Secretary and Life Member Malaysian Information Technology Society (MITS) (since 2008), member of Malaysian Reading Association (MRA)(since December 2000), Member of PKAUKM and Member of UNIKEB. 